\title{
The Experimental Production of Fuel Briquettes from Jamaican Biomass
}

\author{
Dianne Plummer, M.Sc., P.E. ${ }^{*}$, Rémon Goulbourne, \\ Yanique Dickson \\ ${ }^{1}$ University of Technology, Jamaica, Jamaica, dianne.plummer@utech.edu.jm \\ *Corresponding Author, email: dianne.plummer@utech.edu.jm
}

\begin{abstract}
Biomass sources are carbon neutral and are less popular in the Caribbean, especially since many Caricom states lack energy security. This research focuses on determining the characteristics of biomass briquettes produced from banana leaves and sugar cane bagasse with an emphasis on their potential as renewable energy sources. Banana leaves and sugar cane bagasse, are two abundant agricultural wastes in Jamaica. Incorporating the aforementioned biomass waste, with natural cassava starch binder solution and subsequently compressing them, will increase their bulk density. These fibers, having particle sizes $<0.425 \mathrm{~mm}$ and $0.425-2.36 \mathrm{~mm}$ in addition to cassava starch solution $\left(0.05 \mathrm{~g} / \mathrm{cm}^{3}\right.$ and $\left.0.10 \mathrm{~g} / \mathrm{cm}^{3}\right)$ were compressed into briquettes using a compound lever press. This resulted in the banana leaves increasing from a bulk density as low as $0.20 \mathrm{~g} / \mathrm{cm}^{3}$ to a briquette density of $0.39 \mathrm{~g} / \mathrm{cm}^{3}$. The bagasse improved in bulk density from $0.08 \mathrm{~g} / \mathrm{cm}^{3}$ to briquette densities as high as $0.25 \mathrm{~g} / \mathrm{cm}^{3}$. The results indicated that an increase in mechanical durability was observed once there was an increase in the starch binder concentration and a decrease in the particle size. After these actions, the banana leaves briquettes had the lowest durability of $59.17 \%$ at larger particle sizes and low starch concentrations. However, this durability was improved to $99.59 \%$ once the particle sizes were reduced and the starch concentration increased. The high heating values (HHV) were inversely proportional to the binder concentration with the values obtained for the banana fibers being above $17,00 \mathrm{~kJ} / \mathrm{kg}$ at $0.05 \mathrm{~g} / \mathrm{cm}^{3}$ and 16,500 $16,600 \mathrm{~kJ} / \mathrm{kg}$ at $0.10 \mathrm{~g} / \mathrm{cm}^{3}$. The $\mathrm{HHV}$ for the bagasse ranged from $15,400 \mathrm{~kJ} / \mathrm{kg}$ to $17,700 \mathrm{~kJ} / \mathrm{kg}$. The biomass-derived fuels could reduce the dependence on imported fossil fuels, especially with their applications in biomass-fired boilers.
\end{abstract}

Keywords—agricultural waste, biomass, briquettes, energy, renewable

\section{INTRODUCTION}

The term 'bioenergy' is most often used to describe biomass, which is a carbon-based material composed of a mixture of organic molecules containing hydrogen, oxygen, carbon, and nitrogen, but may also include other atoms such as metals and alkali in porphyrins [1]. Furthermore, it may include materials such as bagasse, banana waste, grass, straw, sawdust, coconut husk, and shell and can be densified and pelletized before being combusted for energy [2]. This resulting material is however generally of low density, high moisture content, and proves difficult to store and/or transport. Nevertheless, its advantageous characteristics make it favorable for energy production. Within the Caribbean, biomass has been readily available largely due to the significance of primary industries, namely sugar and banana processing. Agricultural stakeholders

Digital Object Identifier (DOI):

http://dx.doi.org/10.18687/LACCEI2020.1.1.267

ISBN: 978-958-52071-4-1 ISSN: 2414-6390 have been reaping the benefits of this 'waste product' by using and supplying it as both feed and fuel.

Despite these efforts, there are several underutilized feedstocks from a wide array of industries that can be utilized as biomass for energy production. Density is one key parameter for biomass assessment and determines the ease with which feedstock can be transported as well as the ease of storage [3]. Therefore, the densification of biomass is considered important to achieve efficient handling, transport, and storage operations. Densification can enhance volumetric calorific value and physical properties. This leads to clean, stable, and environmentally friendly fuel. Water content is another significant deciding factor for feedstock selection and should be reduced as much as possible. Water not only adds to the weight of the feedstock but can lead to its degradation while in storage and lessen the efficiency of the heating process during energy production.

After pelletization the properties of the pellets and its respective biomass material are different. The pellets are considered as an "upgraded biomass fuel" since, after compression, pellets have a greater energy density than the biomass raw material [4]. The sources of biomass in Jamaica that could be used as a fuel include banana leaves, cardboard, coconut shell, corn husk, coffee husk, sawdust, sugar cane (bagasse), wastepaper, and weeds [5]. Biomass is only considered to be useful as a fuel source when it has a sufficiently high heating value, and according to the U.S. Energy Department, the heating value of a substance is the energy released per unit mass of the substance when the material is fully burnt [6]. For this investigation, due to the abundance and availability of each biomass type in Jamaica, emphasis will be placed on bagasse and banana waste.

There are growing concerns over the use of biomass as fuel particularly with regards to the use of crops and the effects of deforestation [7]. However, these concerns can be eliminated by the use of biomass waste products such as bagasse, banana waste, coconut waste, corn husk, corn stalk, and sawdust. Such sources are readily available in Jamaica and their use will not be a threat to the food supply [5].

Bagasse, a waste product of the sugar refinery process, is the fiber obtained after the juice has been extracted from the plant during the processing of sugar from sugarcane [8]. A Jamaican study done by Landell Mills indicated that to control the waste from the sugar cane process, bagasse would be introduced to boilers on the plant for providing energy and is currently being used along with Bunker C Oil in the boilers of Jamaican sugar refineries [9]. Unfortunately, bagasse cannot be

$1^{\text {th }}$ LACCEI International Multi-Conference for Engineering, Education, and Technology: "Engineering, Integration, and Alliances for a Sustainable Development" "Hemispheric Cooperation for Competitiveness and Prosperity on a Knowledge-Based Economy", July 27-31, 2020, Virtual Edition. 
stored for long periods due to its high moisture content and low bulk density, which causes it to deteriorate rapidly. This inability to store bagasse for extended periods prevents the excess from being used to meet the sugar refinery's internal power needs outside of the sugar cane season (January to midJuly). Pelleting bagasse allows for improved storage of the byproduct during offseason and provides a readily available source of energy. The characteristics of Brazilian biomass such as rice husk, coffee husk, sugar cane bagasse, and sawdust when investigated, revealed that the bagasse and the coffee husk had the second-highest lower heating value (LHV) of $16 \mathrm{MJ} / \mathrm{kg}$ [10]. The highest value was for wood at $17 \mathrm{MJ} / \mathrm{kg}$ while the rice husk had the lowest at $13 \mathrm{MJ} / \mathrm{kg}$. It was also discovered that "the net caloric value of torrefied biomass ranges from 18 to 23 $\mathrm{MJ} / \mathrm{kg}$ (LHV) (dry)" [10].

Previous research by Rose and Myers reported that that 100,000 tonnes of banana were consumed in Jamaica for 2006 [11]. Once bananas are reaped, the leaves and stalk are discarded and the trees are not preserved for new growth and are a great source of discarded biomass[12]. Sellin et al. also studied the suitability of banana leaves and stalk for making fuel briquettes [12]. The study analyzed the biomass before production as well as the produced briquettes. It was found that the high heating value (HHV) of the banana leaves was $17.10 \mathrm{MJ} / \mathrm{kg}$ whereas the stalk was $13.7 \mathrm{MJ} / \mathrm{kg}$ while the respective briquettes were found to have $\mathrm{HHV}$ values of $17.7 \mathrm{MJ} / \mathrm{kg}$ and $14.9 \mathrm{MJ} / \mathrm{kg}$. These results are similar to those of Oliveira Maia et al. who incorporated a similar method to produce briquettes from both banana leaves and stalk [2]. The $\mathrm{HHV}$ values of the banana leave briquettes were $17.7 \mathrm{MJ} / \mathrm{kg}$ while the banana stalk briquettes were $14.9 \mathrm{MJ} / \mathrm{kg}$. These calorific values correlate well with that of sawdust pellets used in a variety of studies having calorific values ranging from $17.0 \mathrm{MJ} / \mathrm{kg}$ to $18.0 \mathrm{MJ} / \mathrm{kg}$. The heating value of the stalk briquette $(14.90 \mathrm{MJ} / \mathrm{kg})$ is comparable to the heating value of rice husk briquettes $(13.39 \mathrm{MJ} / \mathrm{kg})$, but corncob briquettes from the experiment had a much higher heating value of $20.89 \mathrm{MJ} / \mathrm{kg}$ [14]. The heating value of the banana leaves (processed and unprocessed) is much higher than the values for the banana stalk; more energy would be released from the leaves than the stalk during combustion. Consequently, the banana leaves would be more suitable for making fuel pellets.

The bulk and unit density of pellets produced in the pelletization of biomass is a crucial parameter in assessing the efficiency of the densification process. The three crucial factors affecting pellet density are the applied compressive force, screen size, and pellet moisture content [14]. Regarding the compressive force or applied pressure, according to Gilbert et al., higher pressures increased both the density and strength of pellets produced [3]. In this study, strength was analyzed based on the maximum force through the radial plane which the pellet could withstand. The pellet density increased from about 250 $\mathrm{kg} / \mathrm{m}^{3}$ at 55.2 bar to $720 \mathrm{~kg} / \mathrm{m}^{3}$ at 552 bar. There was no significant increase in density between 387 and 552 bar, however. These results are all for switchgrass. Additionally, char combustion will increase with pellet density. Char combustion is an important parameter in analyzing pellet combustion performance [4].

Biomass pellets can be utilized outside of an industrial setting as locally produced charcoal is the main source of heat energy for cooking and other domestic purposes in rural communities. Pellets from the sugar cane and banana waste could function as a low cost and cleaner source of fuel, whilst simultaneously inhibiting deforestation. The pelletization of different biomass types is outlined within this research paper and could be utilized to guide the use of bagasse as a source of energy. Vital information regarding the heating values and benefits of biomass and respective pellets has been summarized and packaged in this article and after reviewing it the reader would gain knowledge of the type of material that would best meet their energy requirement. This research could also be useful to industries keen on utilizing biomass energy sources

\section{MATERIAL \& METHODS}

Dried banana leaves were sorted by removing the midrib from the lamina. Using a heavy-duty blender (CB16), the lamina of the banana leaves was crushed to easily reduce the size of the leaves.

Size variation was achieved by using the U.S.A. Standard Testing Sieve (ASTM E-11 Specification), to ascertain particles of sizes $<0.425 \mathrm{~mm}$ and $0.425 \mathrm{~mm}-2.36 \mathrm{~mm}$

\section{A. Production of Cassava Starch Solution}

The concentrations of $0.1 \mathrm{~g} / \mathrm{cm}^{3}$ and $0.05 \mathrm{~g} / \mathrm{cm}^{3}$ were used for this experiment. For the $0.10 \mathrm{~g} / \mathrm{cm}^{3}, 50 \mathrm{~g}$ of the starch was weighed out and made up to a $500 \mathrm{ml}$ solution. The starch was first dissolved into a small amount of cold water. This was then slowly added hot water while being mixed with a handheld mixer (CHEFMNRJ19) to be made up to 500ml. Upon adding all the starch, the mixing was continued for another twenty seconds. To make the $0.05 \mathrm{~g} / \mathrm{cm}^{3}$, the same procedure was followed using half the mass of starch used for the $0.1 \mathrm{~g} / \mathrm{cm}^{3}$ starch solution.

\section{B. Production of Biomass/Starch Mixture}

$100 \mathrm{~g}$ of the respective biomass type and particle size shown in table 3.0 was measured using the mass balance and added to the required starch solution (also shown in table 3.0). The biomass was mixed with the starch solution using the hand mixer until a homogeneous mixture was achieved. The mixing was done on a hot plate (HP131225) to maintain a temperature at $80^{\circ} \mathrm{C}$.

\section{Densification of Biomass}

$30 \mathrm{~g}$ of the $80^{\circ} \mathrm{C}$ biomass/starch mixture was measured and placed in fabric for compression. The fabric filled with biomass was placed inside the mold cavity and using the compound lever press and compressed for ten minutes. Twenty pounds was placed on the lever to maintain constant pressure while compressing all briquettes. After the biomass was compressed, the fabric and briquette were removed and weighed to obtain the mass after compression. The dimensions 
of each briquette were also measured after compression. This allowed for the calculation of the briquette density immediately after compression. The size of the resulting briquettes was approximately $3.3 \mathrm{~cm}$ long and $3.3 \mathrm{~cm}$ wide.

The briquettes were allowed to dry for 1 day, after which the briquettes were placed in an oven between $100-120^{\circ} \mathrm{C}$ for one hour to dry. After drying, the briquettes were weighed and the density calculated from the new dimensions.

The bulk density of each biomass type and particle size was determined by filling a $25 \mathrm{ml}$ measuring cylinder with each biomass type of particular particle size. The density of each type of biomass briquette was determined by measuring the mass of the briquette using a mass balance (MS30025 /03) and measuring the lengths of the dimensions using a Vernier caliper (CD-4" CX). The mass of the briquettes was then divided by the briquette's volume based on the dimensions measured.

\subsection{Calorific value}

The calorific value of each briquette type was estimated using the ash content and volatile matter. The following equation is the equation used in that calculation:

$$
\mathrm{HHV}=35,430-183.5 \mathrm{VM}-354.3 \mathrm{ASH}
$$

Where $\mathrm{VM}=$ percentage volatile matter of the sample briquette

$\mathrm{ASH}=$ percentage ash content of the sample briquette.

The moisture content was determined by following ASTM E871-82 whereby a $1 \mathrm{~g}$ sample of each briquette type was measured into a crucible and weighed before and after drying. The sample was placed in a furnace (BAF-121212-HT) between $100^{\circ} \mathrm{C}$ and $120^{\circ} \mathrm{C}$ until a constant mass was obtained. To measure the volatile matter, the furnace temperature was increased to $950^{\circ} \mathrm{C}$. Using the ASTM E872 method where the crucible with the constant mass of biomass was then placed in the furnace for 7 minutes at this temperature. After 7 minutes the crucible was removed and weighed to calculate the weight difference. To determine the ash content the crucible with the remaining mass was placed in the oven first at $450-500^{\circ} \mathrm{C}$ for 2 hours then at $700-750^{\circ} \mathrm{C}$ for a further 2 hours. After the four hours, the crucible was removed and weighed for the final mass, this final mass was the remaining ash. A sample calculation of the HHV can be seen in the Appendix.

\section{Durability}

To determine the durability each pellet sample was placed in a bottle with ten marbles and the bottle was inverted 75 times for tumbling the briquette. The mass was weighed before and after the tumbling to determine the percentage durability. Each test was conducted in replicates of three and the average was determined from the three readings

\section{RESULTS AND DISCUSSION}

The smaller particle size of both biomass sources produced briquettes of superior physical quality (higher durability, fewer fines). For the bagasse, however, the smaller particle size produced lower HHV, while the opposite was observed for the banana leaves. Therefore, for the banana leaves, the energy input required for particle size reduction is justified. While bagasse has been studied widely as a fuel, banana leaves provide high $\mathrm{HHV}$, easy particle size reduction, and high durability with less dust. Banana leaves are therefore suitable for further research into characteristics as solid fuels.

Banana fiber briquettes with $0.05 \mathrm{~g} / \mathrm{cm}^{3}$ of starch binder and a particle size of $<436 \mu \mathrm{m}$ provides the highest HHV. Banana of $2.36 \mathrm{~mm}$ particle size had low durability and is therefore unsuitable as a fuel. Higher compression pressures may be needed for this particle size. Bagasse provided high durability at all particle sizes however it is less energy-dense than the banana leaves. Bagasse emits more dust than the banana and therefore provides a higher healthcare hazard.

\section{A. BRIQUETTE DURABILITY}

Based on the European pellet standards, most of the briquettes obtained were within the required range of durability which should be above 97.5\% weight percent [15]. These high durability values are owing to the preheating of the biomass starch mixture before compression. According to Gilbert et al. in the research observing the effect of process parameters on pelletization of herbaceous crops, at $75^{\circ} \mathrm{C}$ to $90^{\circ} \mathrm{C}$, the lignin within the biomass softens thus binding the particles during compression [3]. This was also observed as the biomass mixture was maintained at a temperature of $80^{\circ} \mathrm{C}$ before compression. Additionally, cooling the lignin within the compressed biomass would harden increasing the briquette strength [3].

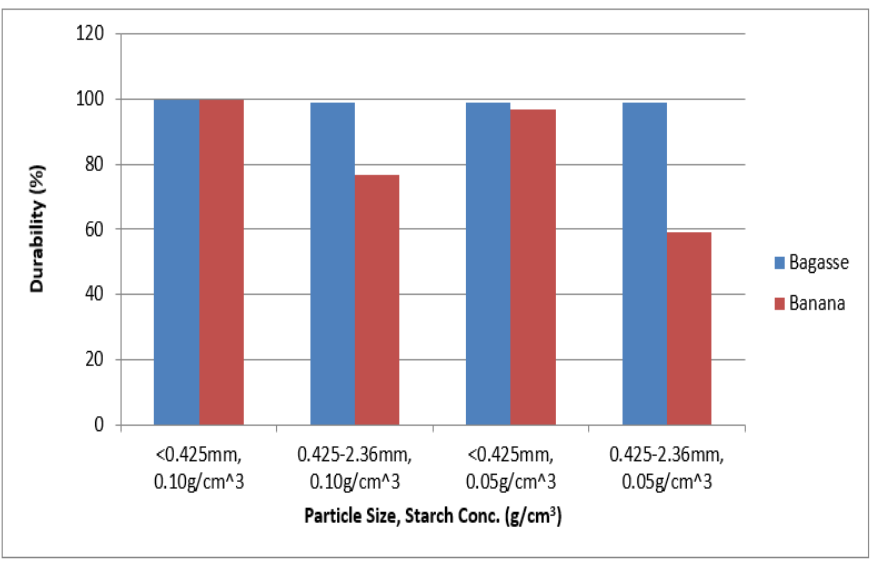

Figure 1.0: Effect of Biomass Type on the Durability of the Briquettes 


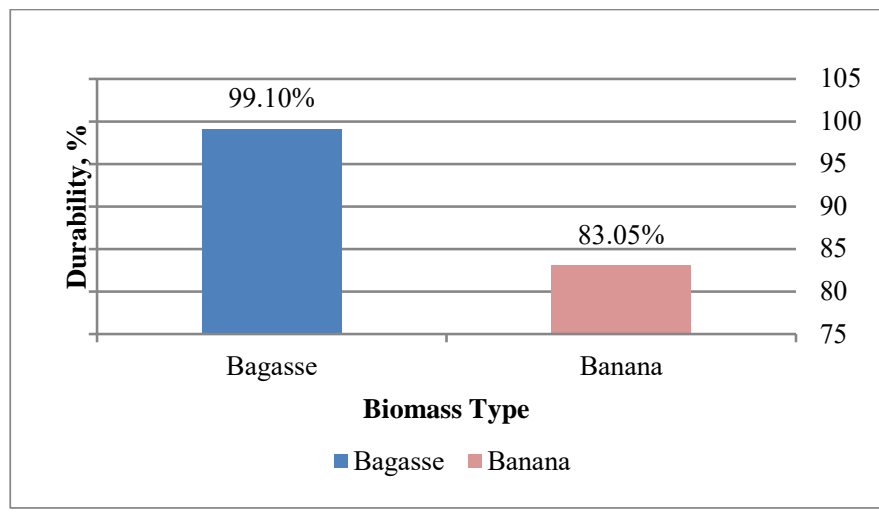

Figure 1.1: Effect of Biomass Type on the Average Durability of Biomass Briquettes

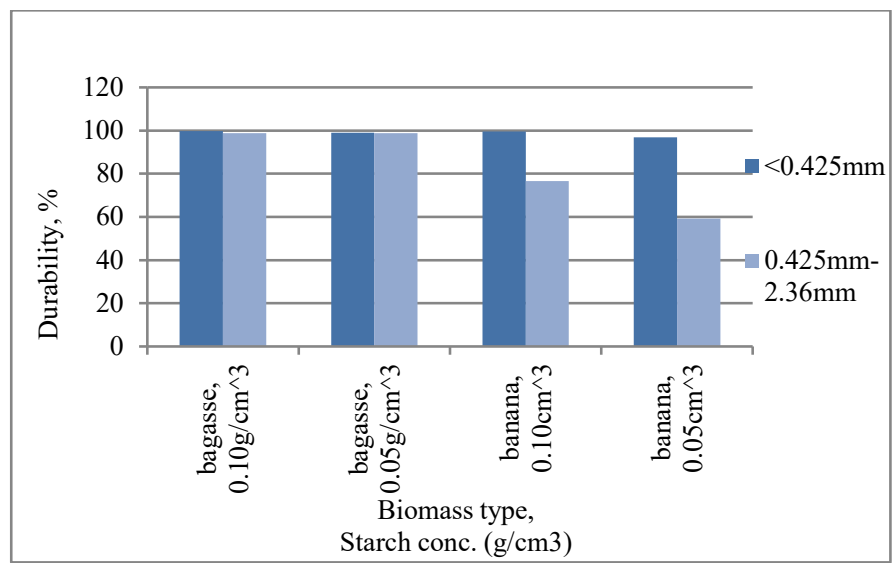

Figure 1.2: Effect of Particle Size on the Durability of Biomass Briquettes

\section{B. Effect of particle size.}

There was a slight improvement in the durability of the bagasse briquettes moving from large particles $(<0.425 \mathrm{~mm})$ to fine particles $(0.425 \mathrm{~mm}-0.236 \mathrm{~mm})$. Nonetheless, the values were close, ranging from $98.79-98.82 \%$ for large particles to 98.95\%-99.85\% for the larger particles (Figure 1.1).

Regarding the banana leaves, significant improvements were made once the size of the particles was reduced. An example of this is seen when analyzing the banana briquettes at $0.05 \mathrm{~g} / \mathrm{cm}^{3}$. In Figure 1.0, the briquettes of fine particles gave average durability of $96.82 \%$ while the larger particles were hardly durable at $59.17 \%$. Though at $0.10 \mathrm{~g} / \mathrm{cm}^{3}$ the durability of the large particles was improved to $76.63 \%$, there was even more improvement for the small particles at this concentration having a durability of $99.59 \%$, the second-highest durability overall. These differences in durability along the particle sizes can be explained by the surface area of the particles. These results are consistent with those of Huko, Kamau, and Ogola in which, the effect of varying particle sizes on the mechanical properties of biomass pellets was investigated [16]. In that research, it was found the durability of the pellets was inversely proportional to the particle sizes. The smaller the particles were, the greater the surface area was for contact with the binder and this resulted in increased gelatinization and therefore improved [16].

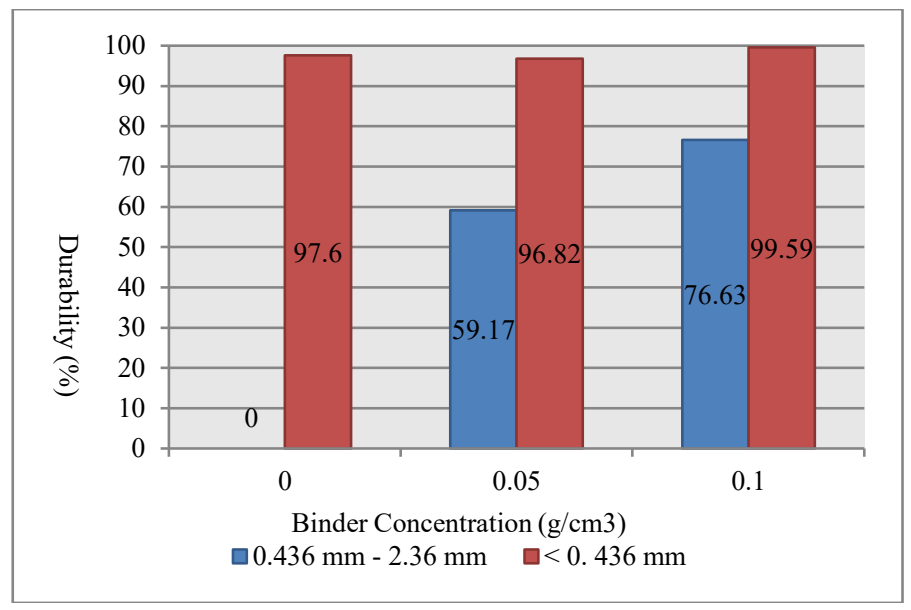

Figure 1.3: Effect of Binder Concentration on Durability of Banana Briquettes

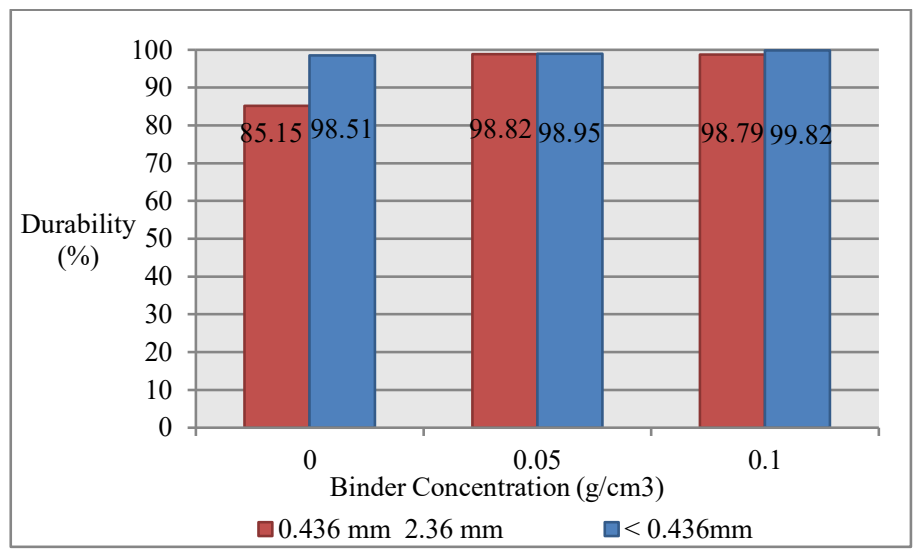

Figure 1.4: Effect of Binder Concentration on Durability of Bagasse Briquettes

The binder had a significant effect on the durability of the briquettes made from the large banana particles. Although there was a significant increase, the durability of these briquettes was still below an acceptable level. The highest durability obtained was $99.82 \%$ (Figure 1.4). There was high attrition of particles from the briquettes while being handled and transported in the laboratory. This loss of mass inherently reduces the efficiency of energy production from this biomass as a consumer will receive less fuel than desired or a producer will be able to deliver less than initially planned. They would, therefore, be unsuitable for use as a fuel.

The binder's presence had a less significant effect on the durability of briquettes made from the $<436 \mu \mathrm{m}$ particles. This result agrees with that of Adapa, Tabil, \& Schoenau, who found that particle size influences durability [17]. Banana fibers without a binder had a durability of $97.6 \%$. The $0.05 \mathrm{~g} / \mathrm{cm}^{3}$ starch concentration decreased the durability by $0.78 \%$, while 
the $0.1 \mathrm{~g} / \mathrm{cm}^{3}$ concentration increased it by $1.99 \%$ to a maximum of $99.59 \%$, the highest observed for the banana in this study. Using a minimum starch concentration yields cost savings.

\section{Calorific Value}

Comparison of Figures 1.5 and 1.6 show that banana leaf briquettes generally displayed higher calorific values and energy densities than their bagasse counterparts. The banana fiber briquettes had higher energy densities than the bagasse (Figure 1.7). The average calorific value calculated for all 4 banana samples with the binder was $16,996 \mathrm{~kJ} / \mathrm{kg}$. The value compares favorably with the range of $17,100 \mathrm{~kJ} / \mathrm{kg}-17,700$ $\mathrm{kJ} / \mathrm{kg}$ measured by de Oliveira Maia, et al. [2]. In that study, dried banana leaves were compressed into briquettes using a hydraulic press and no binder. Particle size of $2.5 \mathrm{~mm}$ was used.

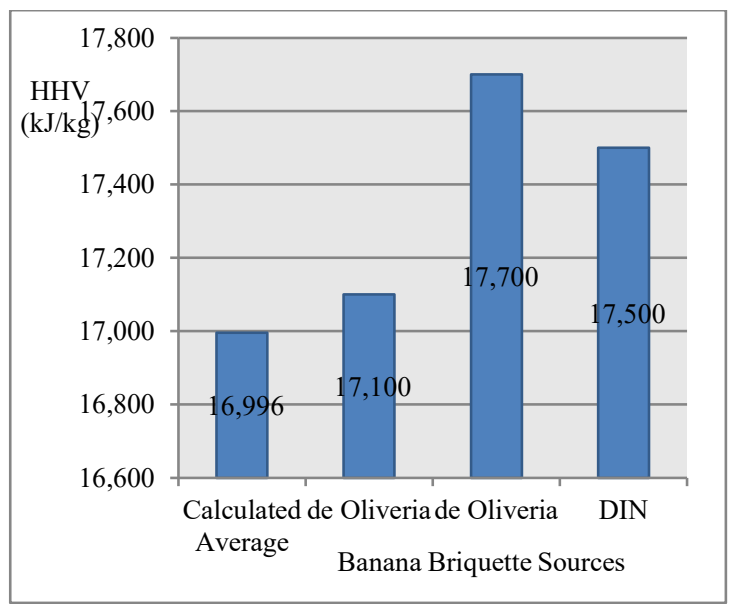

Figure 2.5: Comparison of the HHV Obtained from the Banana Briquettes to HHVs of Previous Research

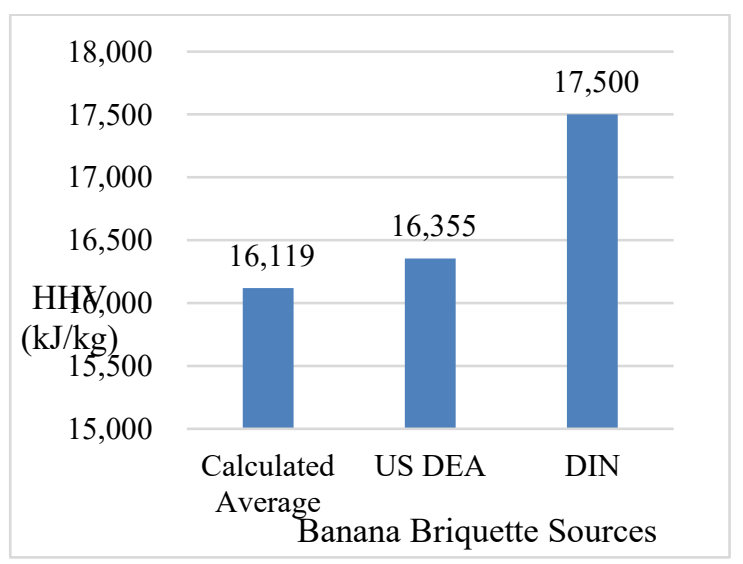

Figure 2.6: Comparison of the HHV Obtained from the Bagasse Briquettes to HHVs of Previous Research

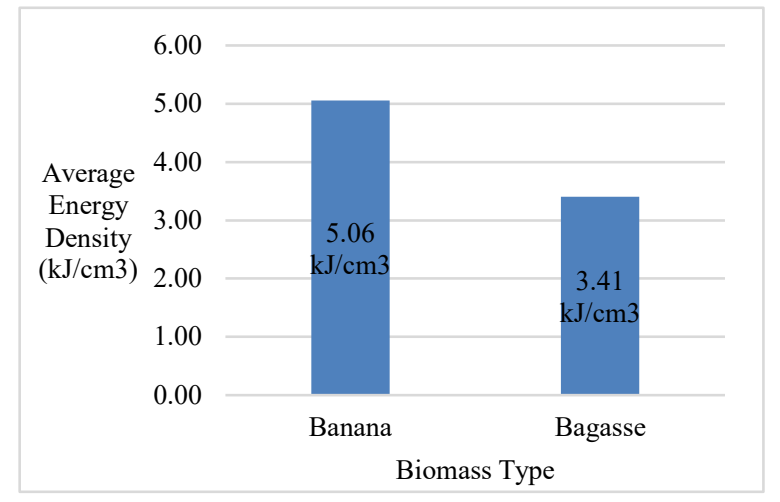

Figure 1.7: Average Energy Density of Banana Leaves and Bagasse Briquettes $(\mathrm{kJ} / \mathrm{cm} 3)$

The difference in calorific value can be attributed to the difference in the methodology applied. De Oliveira Maia et al used an unspecified mill for particle size reduction, and the $\mathrm{HHV}$ was determined using a Bomb Calorimeter according to ABNT MB-2850 and ABNT NBR 8628 standards [2]. In this study, a blender was used for particle size reduction and the HHV was calculated using an equation developed by Cordero [18]. The variables in this equation were the ash content and volatile matter which were obtained from proximate analysis of the biomass using ASTM standards.

While Cordero used a wide range of lignocellulosic material in developing the equation, banana leaves were not used [18]. Therefore the difference between the calculated values and those that would be obtained from a bomb calorimeter is unknown.

For the bagasse, an average of $16,119 \mathrm{~kJ} / \mathrm{kg}$, with a maximum of $17,523 \mathrm{~kJ} / \mathrm{kg}$ and a minimum of $15,407 \mathrm{~kJ} / \mathrm{kg}$ was calculated. The literature reviewed provided a range for sugarcane bagasse of $16,355 \mathrm{~kJ} / \mathrm{kg}^{1}$ to $16,462 \mathrm{~kJ} / \mathrm{kg}^{1}$.

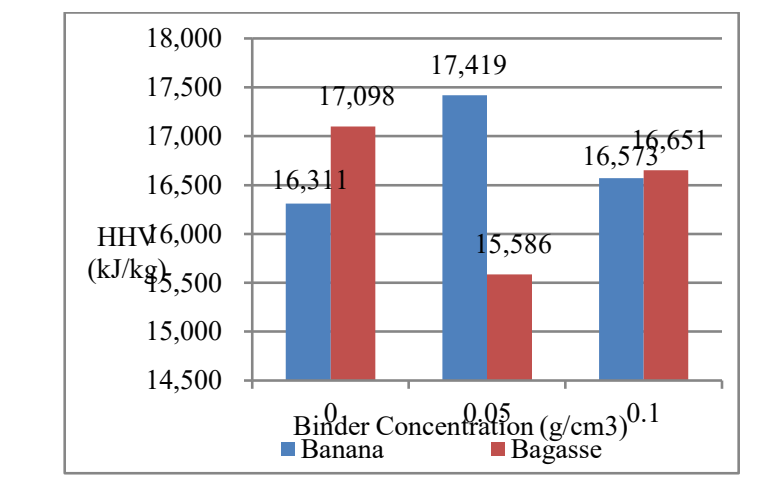

Figure 1.8: Effect of the Binder Concentration on HHV of the Biomass Briquettes

As indicated by Figure 1.8, the lower concentration of starch binder gave the highest calculated calorific value. 
Additionally, the bagasse samples with no starch binder produced higher calorific values than those with starch. For the banana leaves, at both particle sizes, the increase in binder concentration led to increases in the calorific value (Figure 1.8). This increase is greatly beneficial, as the improvements in durability, density, reduction in dust, and increase in HHV help to offset the costs associated with binder usage.

The opposite was true for the bagasse, as shown in figure 1.8, with the HHV of the bagasse decreasing by approximately $1,500 \mathrm{~kJ} / \mathrm{kg}$ with the addition of $0.05 \mathrm{~g} / \mathrm{cm}^{3}$ of the binder. The decrease was less significant when more binder was added. The decrease in HHV provides a major disadvantage as any improvements in durability would be nullified by energy losses. The decrease in HHV with the addition of a binder was also observed by Zakari, et al., in which briquettes were made using sawdust with $1 \mathrm{~cm}$ particle sizes and starch was added as a binder [19].

Emerhi compared the efficacy of three organic binders (cassava starch with cow dung and wood ash) for briquettes [20]. The findings indicated that cassava starch provided the greatest increase in HHV in the biomass tested. Bagasse and banana were not used in that study, however, and a particle size of $6-8 \mathrm{~mm}$ was used in that study- much larger than the range used in this work. Additionally, the concentrations of cassava starch used in the aforementioned research are unknown.

According to Zakari, et al., the efficacy of a binder is greatly dependent on the elemental composition of the biomass [19. Based on the elemental composition of the bagasse, the starch binder could have modified the combustion characteristics of the bagasse significantly. This change in combustion characteristics explains the deviation from the expected trend.

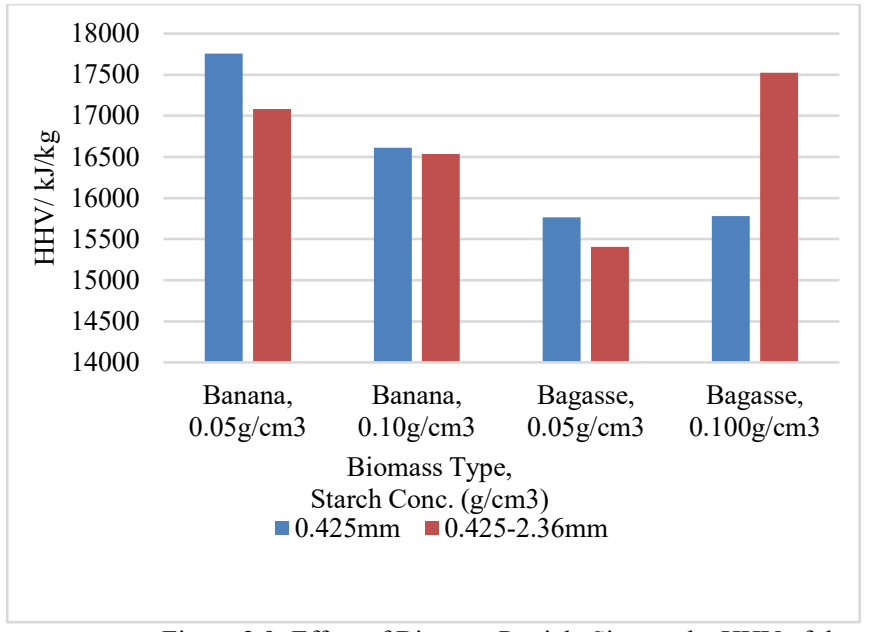

Figure 2.9: Effect of Biomass Particle Size on the HHV of the Briquettes

The particle size of the banana increases the calorific value, and more energy is released from the banana as the particles become smaller. The increased energy content is a necessary trade-off for the energy input required to reduce the particle size. For the banana fiber briquette, the calorific value increased from $17,083 \mathrm{~kJ} / \mathrm{kg}$ to $17,755 \mathrm{~kJ} / \mathrm{kg}$ as the particle size was decreased to $0.05 \mathrm{~g} / \mathrm{cm}^{3}$ starch concentration (Figure 1.9). At the higher concentration, the calorific value increased from $16,533 \mathrm{~kJ} / \mathrm{kg}$ to $16,612 \mathrm{~kJ} / \mathrm{kg}$ as the particle size was decreased. This trend continued with the banana samples containing no binder, as the calorific value increased from $16,119 \mathrm{~kJ} / \mathrm{kg}$ to $16,501 \mathrm{~kJ} / \mathrm{kg}$ with a decrease in particle size.

For the bagasse, the HHV increased as the particle size increased [21]. The particle size reduction process reduced the volatile matter of the bagasse. Therefore the HHV reduction was observed. The bagasse would have undergone a more intense particle size reduction process at the Monymusk factory than the banana leaves would have experienced in the heavyduty blender.

The densities of the briquettes obtained ranged from $0.18 \mathrm{~g} / \mathrm{cm}^{3}$ to $0.39 \mathrm{~g} / \mathrm{cm}^{3}$ (Figure 1.11). These values are significantly lower than the densities obtained in previous research of this nature. The study of producing biomass briquettes from a banana culture obtained a density ranging from $1-0.99 \mathrm{~g} / \mathrm{cm}^{3}$ for both banana leaves briquettes and banana pseudostem briquettes [12]. This significant decrease in density could be due to the differences in compaction pressures and machinery used. A briquette hydraulic press was used executing a compaction pressure of $18 \mathrm{MPa}$ [12]. Gilbert et al. used up to 500bar (50MPa) of compressive pressure in the formation of switchgrass pellets which had densities of up to $800 \mathrm{~kg} / \mathrm{m}^{3}$ $\left(0.8 \mathrm{~g} / \mathrm{cm}^{3}\right)$ [3]. For this research, however, a lever press was used with a compaction force.

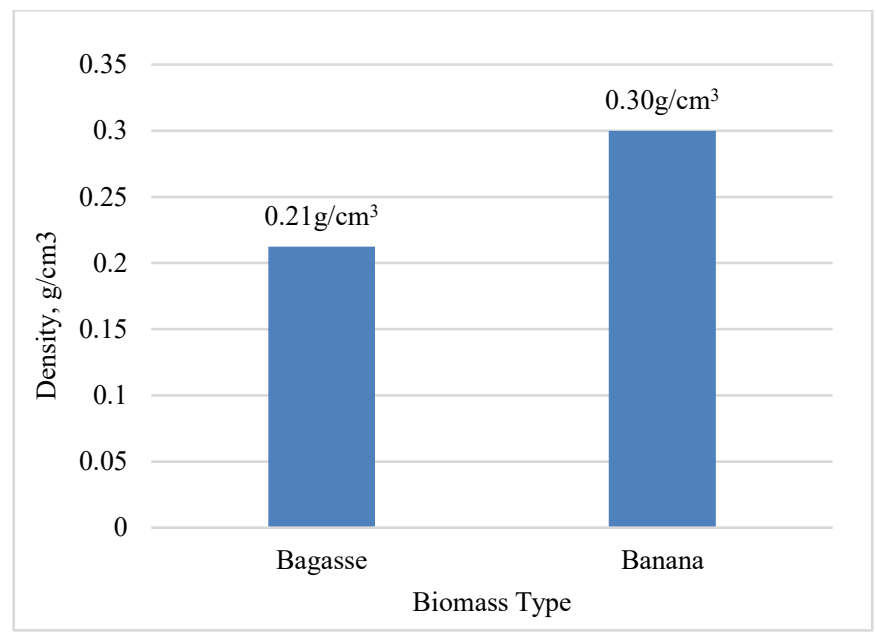

Figure 1.10: Effect of Biomass type on the Resulting Density of Biomass Briquettes

\section{Bulk density of banana leaves and bagasse.}

Despite these low densities, an improvement in density was seen when analyzing the bulk densities of the biomass types from the original form to the reduced form to the compressed form. For the banana leaves, for example, it is seen 
that the bulk density of the leaves was $0.042 \mathrm{~g} / \mathrm{cm}^{3}$. After carrying out the size reduction technique, blending, the density of the larger particles, $0.425 \mathrm{~mm}-2.36 \mathrm{~mm}$, was $0.20 \mathrm{~g} / \mathrm{cm}^{3}$ while the density of the smaller range $<0.425 \mathrm{~mm}$ was 0.29 $\mathrm{g} / \mathrm{cm}^{3}$. In the case of the bagasse, a similar trend in the density was noticed with a gradual increase in the density as the particle sizes were reduced. The bagasse bulk density was $0.08 \mathrm{~g} / \mathrm{cm}^{3}$. After sieving the bagasse the larger size range, as in the banana leaves, was $0.08 \mathrm{~g} / \mathrm{cm}^{3}$ while the density of the smaller range was $0.09 \mathrm{~g} / \mathrm{cm}^{3}$. These results align with those of Mani et al. where the effects of compressive force particle size and moisture content on biomass pellets from grass were studied [14]. It was also observed that as the size of the particles increased the bulk density of the biomass types lowered. The increase in bulk density as the particle size decreases can be accounted to less space in between the individual particles in the measuring cylinder for smaller particle sizes therefore more mass can fit in the container [14]. It was important to note that despite the lower density of the banana leaves when compared to the un-sieved bagasse, after blending the bulk density was much higher than that of the bagasse.

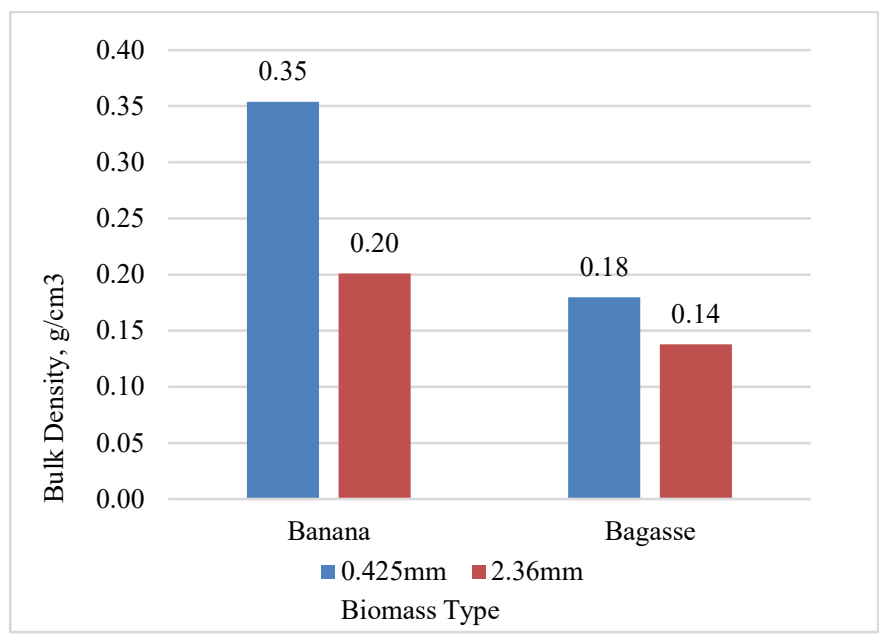

Figure 1.11: Bulk Density of the Banana leaves and Bagasse at Different Particle Sizes

The average densities of banana leaf briquettes were greater than those of the bagasse briquettes at any respective particle size and starch concentration (Figure 1.11). For example, at $0.10 \mathrm{~g} / \mathrm{cm}^{3}$ and within the size range of $<0.425 \mathrm{~mm}$ the banana briquette had a higher density at $0.39 \mathrm{~g} / \mathrm{cm}^{3}$ while the bagasse was $0.25 \mathrm{~g} / \mathrm{cm}^{3}$. These were also the highest densities overall for the banana and the bagasse respectively. The average densities for the banana leave briquettes can be explained by the trend seen in the bulk densities where the banana leaves at reduced particle size were more compact than the bagasse. With this behavior it can be assumed that the banana leaves are more compressible than the bagasse.

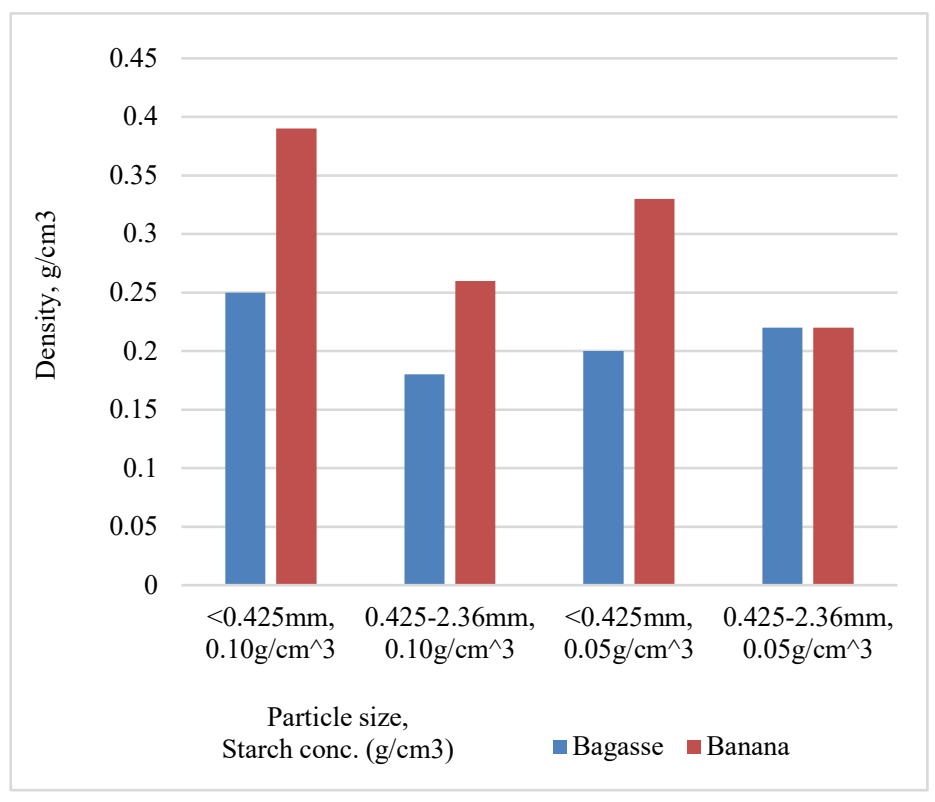

Figure 1.12: Effect of Biomass Type on the Density of the Briquettes

\section{E. Effect of particle size.}

It was notable that the densities at $<0.425 \mathrm{~mm}$ particle size and $0.10 \mathrm{~g} / \mathrm{cm}^{3}$ concentration were the highest for the respective biomass types. For both biomass types, it was observed that as the particle size decreases the density of the briquettes increases. This indicated that at smaller particle sizes the compressibility of the biomass increased. This agreed with the results from Zafari and Kianmehr which used composted municipal solid waste to produce fuel briquettes where 1.5, 0.9, and $0.3 \mathrm{~mm}$ particle sizes were used [22]. It was found that smaller particle sizes would generate higher densities since smaller particle sizes have a larger surface area for bonding during compression. The bagasse at $0.05 \mathrm{~g} / \mathrm{cm}^{3}$ starch concentration was however an exception to this trend as the density slightly decreased from $0.22 \mathrm{~g} / \mathrm{cm}^{3}$ at the size range of $0.425 \mathrm{~mm}-2.36 \mathrm{~mm}$ to $0.20 \mathrm{~g} / \mathrm{cm}^{3}$ at the smaller size range. This exception could be a result of the low compressive force used for this research. Mani et al. used up to $1,000 \mathrm{~N}$ to $4,400 \mathrm{~N}$, however, the design of the compound lever press used made it impossible for the use of such heavy loads [14]. 


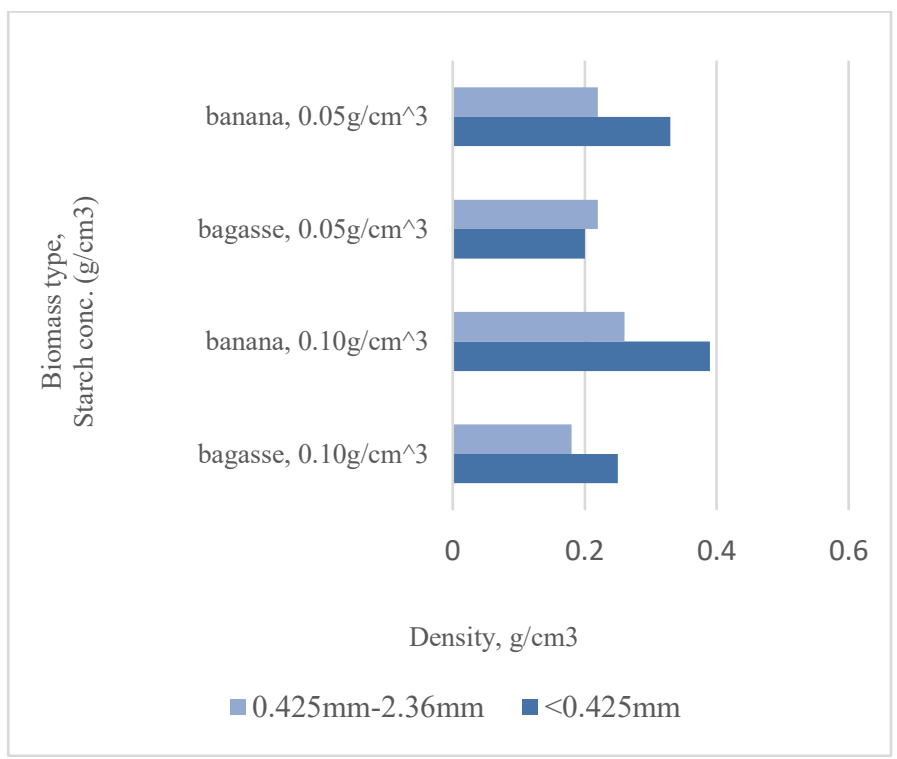

Figure 2.13: Effect of Particle Size on the Density of the Briquettes

\section{LIMITATIONS AND FUTURE WORK}

Further studies could elucidate the minimum binder concentration that will yield improved durability and reduced fines attrition. While the $0.1 \mathrm{~g} / \mathrm{cm}^{3}$ concentration provided the highest durability, further studies could determine the efficacy of concentrations between $0.05 \mathrm{~g} / \mathrm{cm}^{3}$ and $0.1 \mathrm{~g} / \mathrm{cm}^{3}$ in binding these banana particles.

More analysis is required to determine what increase in HHV should be expected based on binder concentration in these briquettes.

The particle sizes could have played a role in the HHV reduction. Further analysis of the bagasse combustion could be done to further assess these results.

With the strong correlation between carbon content and $\mathrm{HHV}$, the further elemental analysis would be required to determine the carbon content of the biomass used in this study.

The calorific value is strongly correlated to the biomass' carbon content [19]. Therefore, elemental analysis of the two biomass sources could assist in determining the cause of the differences. If the blended banana had a higher carbon content per unit mass than the bagasse due to the pre-treatment process, then a higher calorific value would be expected for the banana.

In concluding, understanding the characteristics of the locally available biomass will facilitate the best briquette manufacturing options. These can then be used to offset fuel costs in the sugar industry and further pave the way for the Caribbean islands to improve their energy security.

\section{ACKNOWLEDGMENT}

The compilation of this research paper would not have been possible were it not for the input and assistance of many key individuals. Whilst many can be credited for their sterling contributions, the authors wish to specifically recognize the efforts of the following persons and institutions. The University of Technology, Jamaica, Murna Plummer, Berlyn Christie, Odian Barret, Shaneque Edwards. To all relatives, wellwishers, and colleagues who have offered their continued support

\section{REFERENCES}

[1] Biomass Energy Centre (2011). What is Biomass? Retrieved from http://www.biomassenergycentre.org.uk/portal/page?_pageid=76,15049\& dad=portal

[2] De Oliveira Maia, B., Souzab, O., Marangonib, C., Hotzaa, D., Oliveiraa, A. d., \& Sellin, N. (2014). Production and Characterization of Fuel Briquettes from Banana Leaves Waste. Chemical Engineering Transactions, 439-444.

[3] Gilbert, P., Ryu, C., Sharifi, V., \& Swithenbank, J. (2009). Effect of Process Parameters on Pelletisation of Herbaceous Crops. Fuel, 88(8), 1491-1497.

[4] Rhén, C., Öhman, M., Gref, R. \& Wästerlund, I. (2006). Effect of Raw Material Composition in Woody Biomass Pellets on Combustion Characteristics. Biomass and Bioenergy, 31(1), 66-72.

[5] Brown, A. (2012, July 8). Biomass Briquettes: An Energy Option for Jamaica. The Jamaica Observer. Retrieved from http://www.jamaicaobserver.com/magazines/career/Biomass-briquettes-An-energy-option-for-Jamaica_11772575

[6] (2012). Biomass Energy Data Book: The Effect of Moisture on Heating Values. $\quad$ Retrieved from http://cta.ornl.gov/bedb/appendix_a/The_Effect_of_Moisture_on_Heating Values.pdf

[7] Mata, T. M., Caetano, N. S., Costa, C. A., Sikdar, S. K., \& Martins, A. A. (2013). Sustainability Analysis of Biofuels Through the Supply Chain Using Indicators. Sustainable Energy Technologies and Assessments, 3, 53-60.

[8] BioGreenChoice (2014). Questions about Bagasse/Sugarcane? Retrieved from http://www.biogreenchoice.com/category_s/1864.htm

[9] Landell Mills Ltd (2012). Biomass Feedstock and Cogeneration in the Sugar Industry of Jamaica. Retrieved from http://www.pcj.com/dnn/Portals/0/Documents/FinalReport-May-092012\%20Landell\%20Mills\%20Biomass\%20Report.pdf

[10]Missagia, B., Corrêa, M. F., Ahmed, I., Krautz, H. \& Ay, P. (2009). Comparative Analysis of Brazilian Residual Biomass for Pellet Production. Implementing Environmental and Resource Management, 7-14. DOI 10.1007/978-3-540-77568-3_2

[11]Rose, R. and Myers, J. (2008). Jamaica Giving Up on Export Bananas Local Consumption Triples Foreign Sales. Retrieved from http://jamaicagleaner.com/gleaner/20080806/business/business4.html

[12]Sellin, N., Oliveiraa, B. G., Marangonia, C., Souza, O., Oliveirab, A. P \& Oliveira, T. M. (2013).Use of Banana Culture Waste to Produce Briquettes. The Italian Association of Chemical Engineering, 23, 349-354.

[13]Oladeji, J. T. (2010). Fuel Characterization of Briquettes Produced from Corncob and Rice Husk Resides. The Pacific Journal of Science and Technology, 11 (1), 101-106.

[14]Mani, S., Tabil, L.G. and Sokhansanj, S. (2005). Specific Energy Requirement for Compacting Corn Stover. Bioresource Technology, 97, $1420-1426$.

[15]WIP Renewable Energies and Holzforschung Austria (2009). Advancement of Pellets-Related European Standards. Retrieved from http://ec.europa.eu/energy/intelligent/projects/sites/ieeprojects/files/projects/documents/pelletslas_pellet_standards.pdf

[16]Huko, D., Kamau, D.N. and Ogola, W.O. (2015). Effects of Varying Particle Size On Mechanical and Combustion Characteristics of Mango Seed Shell Cashew Nut Shell Composite Briquettes. International Journal of Engineering Science Invention, 4(5), 48-58. http://www.ijesi.org/
Digital Object Identifier:

ISSN, ISBN: 
[17]Adapa, P., Tabil, L., \& Schoenau, G. (2011). Grinding Performance and Physical Properties of Non-Treated and Steam Exploded Barley, Canola, Oat and Wheat Straw. Journal of Biomass and Bioenergy, 549-561.

[18]Cordero, T., Marquez, F., Rodriguez-Mirasol, J., \& Rodriguez, J. (2001). Predicting Heating Values of Lignocellulosics and Carbonaceous Materials from Proximate Analysis. Fuel, 1567-1571.

[19]Zakari, I. Y., Ismaila, A., U, S., \& R, N. (2013). Investigation on the Effects of Addition of Binder and Particle Size on the High Calorific Value of Solid Biofuel Briquettes. Journal of Natural Sciences Research, 30-34.

[20]Emerhi, E. (2011). Physical and combustion properties of briquettes produced from sawdust of three hardwood species and different organic binders. Advances in Applied Science Research, 236-246.

[21]Overend, R., Milne, T., \& Mudge, L. (1985). FUndamentals of Thermochemical Biomass Conversion. New York: Elsevier Applied Science Publishers.

[22]Zafari and Kianmehr (2012). Effect of Raw Material Properties and Die Geometry on the Density of Biomass Pellets from Composted Municipal Solid Waste. BioResource 7(4), 4704-4714. 